\title{
Lymphatic invasion is a significant indicator of poor patient prognosis in lung squamous cell carcinoma
}

\author{
RYOTA MASUDA $^{1}$, HIROSHI KIJIMA ${ }^{2}$, MADOKA NITO ${ }^{1}$, ATSUSHI WADA ${ }^{1}$, \\ TOMOHIKO MATSUZAKI ${ }^{1}$, YOICHIRO IKOMA ${ }^{1}$, KENEI NAKAZATO ${ }^{1}$, DAISUKE MASUDA ${ }^{1}$, \\ MAKIKO TANAKA $^{3}$, HIROYUKI KOBAYASHI ${ }^{4}$, SADAKI INOKUCHI ${ }^{3}$ and MASAYUKI IWAZAKI ${ }^{1}$ \\ ${ }^{1}$ Department of General Thoracic Surgery, Tokai University School of Medicine, Isehara, Kanagawa 259-1193; \\ ${ }^{2}$ Department of Pathology and Bioscience, Hirosaki University Graduate School of Medicine, \\ Hirosaki, Aomori 036-8562; Departments of ${ }^{3}$ Critical Care and Emergency Medicine and ${ }^{4}$ Clinical Pharmacology, \\ Tokai University School of Medicine, Isehara, Kanagawa 259-1193, Japan
}

Received August 15, 2015; Accepted August 22, 2016

DOI: $10.3892 / \mathrm{mmr} .2017 .6256$

\begin{abstract}
Pathological stage is the most important prognostic factor in patients with lung cancer, and is defined according to the tumor node metastasis classification system. The present study aimed to investigate the clinicopathological significance of lymphatic invasion in 103 patients who underwent surgical resection of lung squamous cell carcinoma (SqCC). The patients were divided into two groups, according to the degree of lymphatic invasion: Those with no or mild lymphatic invasion (ly0-1) and those with moderate or severe lymphatic invasion (ly2-3). Ly2-3 was associated with tumor size $(\mathrm{P}=0.028)$, lymph node metastasis $(\mathrm{P}<0.001)$, venous invasion $(\mathrm{P}=0.001)$ and histological differentiation $(\mathrm{P}=0.047)$. Statistical analysis using the Kaplan-Meier method and the log-rank test indicated that overall survival was significantly reduced in patients with ly2-3 compared with those with ly0-1 ( $<<0.001)$. Multivariate analysis identified ly2-3 as an independent predictor of mortality (hazard ratio, 2.580; 95\% confidence interval, 1.376-4.839). In conclusion, moderate or severe lymphatic invasion (ly2-3) indicated a high malignant potential and may be considered an independent predictor of poor prognosis in patients with $\mathrm{SqCC}$ of the lung.
\end{abstract}

\section{Introduction}

Cancer stage is defined according to the International Union against Cancer tumor node metastasis (TNM) classification system (1). Other characteristics, including histological differentiation, tumor infiltration (INF) pattern, stromal type,

Correspondence to: Dr Hiroshi Kijima, Department of Pathology and Bioscience, Hirosaki University Graduate School of Medicine, 5 Zaifu-cho, Hirosaki, Aomori 036-8562, Japan

E-mail: hkijima@hirosaki-u.ac.jp

Key words: lung cancer, squamous cell carcinoma, lymph node metastasis, prognosis blood vessel invasion and lymphatic invasion are also used to assess tumors (2-4). These other characteristics are not used to determine pathological stage; however, some studies have reported that they may help to predict outcomes (2-10). Some patients with lung cancer only undergo limited resection due to poor lung function $(11,12)$. Patients with lung squamous cell carcinoma (SqCC) occasionally exhibit chronic obstructive pulmonary disease due to smoking $(13,14)$, and often require limited lung resection without systematic lymph node dissection. In these cases, the lymph nodes, which are the $\mathrm{N}$ factor in the TNM classification system, cannot be pathologically evaluated, and thus the pathological stage cannot be determined. Therefore, it is difficult to evaluate the need for adjuvant chemotherapy and radiotherapy, and to predict prognosis.

In our previous study, we examined the INF pattern in lung SqCC specimens; the samples were divided into two groups: The INFc(-) group, which exhibited clear borders between the tumor and surrounding normal tissues, and the INFc(+) group, which did not exhibit clear borders between the tumor and surrounding normal tissues $(6,15-17)$. The results demonstrated that $\mathrm{INFc}(+)$ was significantly associated with venous invasion, scirrhous stromal type and poorer postoperative survival, thus suggesting that $\operatorname{INFc}(+)$ may be considered a useful marker of local invasiveness. Determination of various histological characteristics of primary lesions are important for patients with recurrent lung SqCC, since there are few therapeutic options available for these patients compared with patients with adenocarcinoma (18-24). Histological vascular invasion has been reported to predict prognosis in non-small cell lung cancer (8-10). Several studies regarding non-small cell lung cancer have predominantly focused on patients with adenocarcinoma, whereas no previous studies have focused specifically on patients with SqCC, to the best of our knowledge (8-10). The present study investigated the association between the degree of lymphatic invasion and prognosis in patients with SqCC of the lung. The aim of the present study was to investigate whether the pattern of lymphatic invasion and other clinicopathological characteristics may be used to predict prognosis in patients with SqCC of the lung. 
A

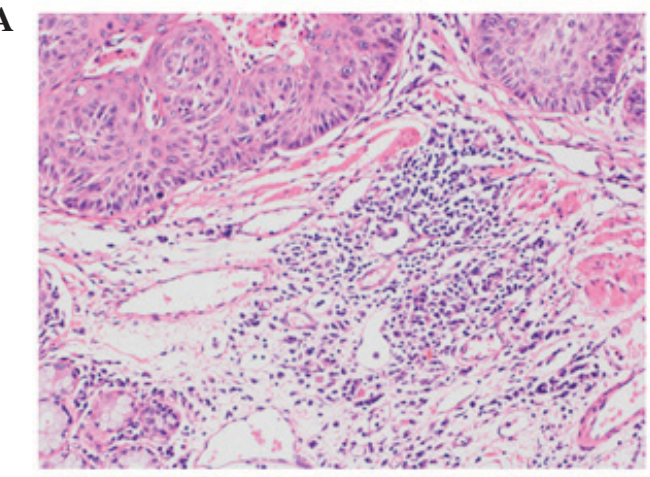

C

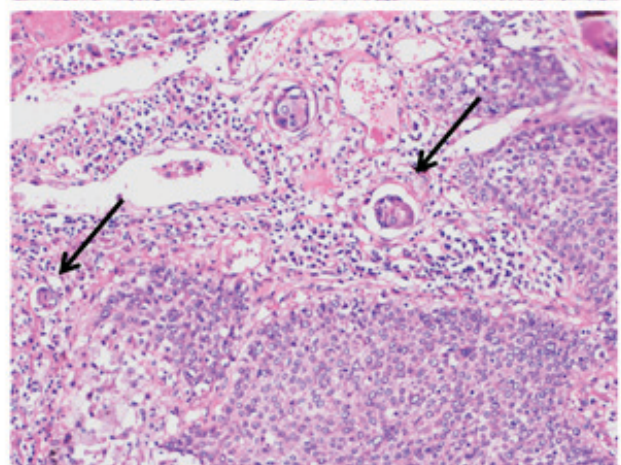

B

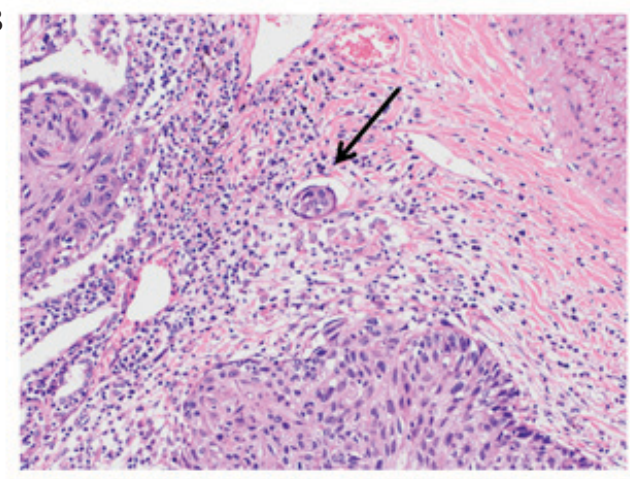

D

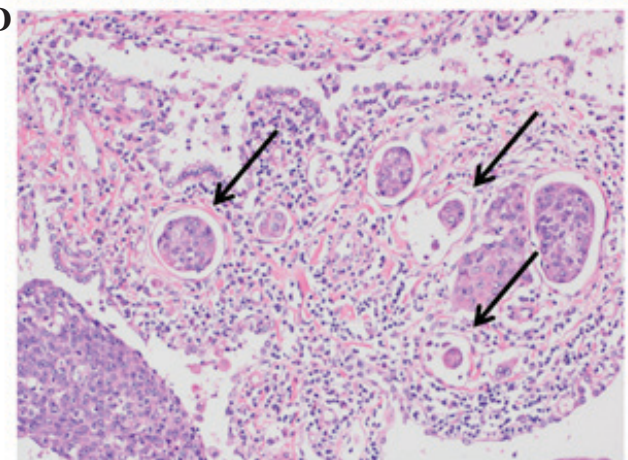

Figure 1. Microscopic images of lung squamous cell carcinoma samples (hematoxylin and eosin staining). (A) No lymphatic invasion, (B) mild lymphatic invasion, (C) moderate lymphatic invasion and (D) severe lymphatic invasion. Arrows indicate foci of lymphatic invasion. Original magnification, x200.

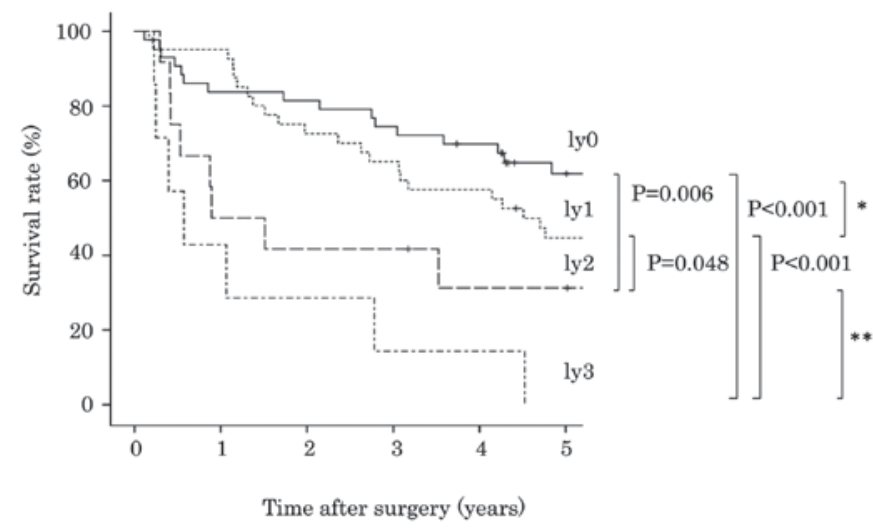

Figure 2. Degree of lymphatic invasion and cumulative survival of patients with lung squamous cell carcinoma. ${ }^{*} \mathrm{P}=0.237,{ }^{* *} \mathrm{P}=0.138$; Kaplan-Meier method and log-rank test.

\section{Materials and methods}

Lung cancer specimens. Resected specimens were collected from patients treated for $\mathrm{SqCC}$ of the lung. The samples were examined after receiving informed consent from the patients. The study protocol was approved by the Institutional Review Board of Tokai University Hospital (Isehara, Japan). The present study included 103 patients with SqCC of the lung (97 males and 6 females; age range, 43-85 years; mean age, $67.2 \pm 9.1$ years) who underwent radical surgery (lobectomy and mediastinal lymphadenectomy) at Tokai University Hospital. For each patient, tumor stage was defined according to the TNM classification system (25) and the histological type was defined according to the World Health Organization
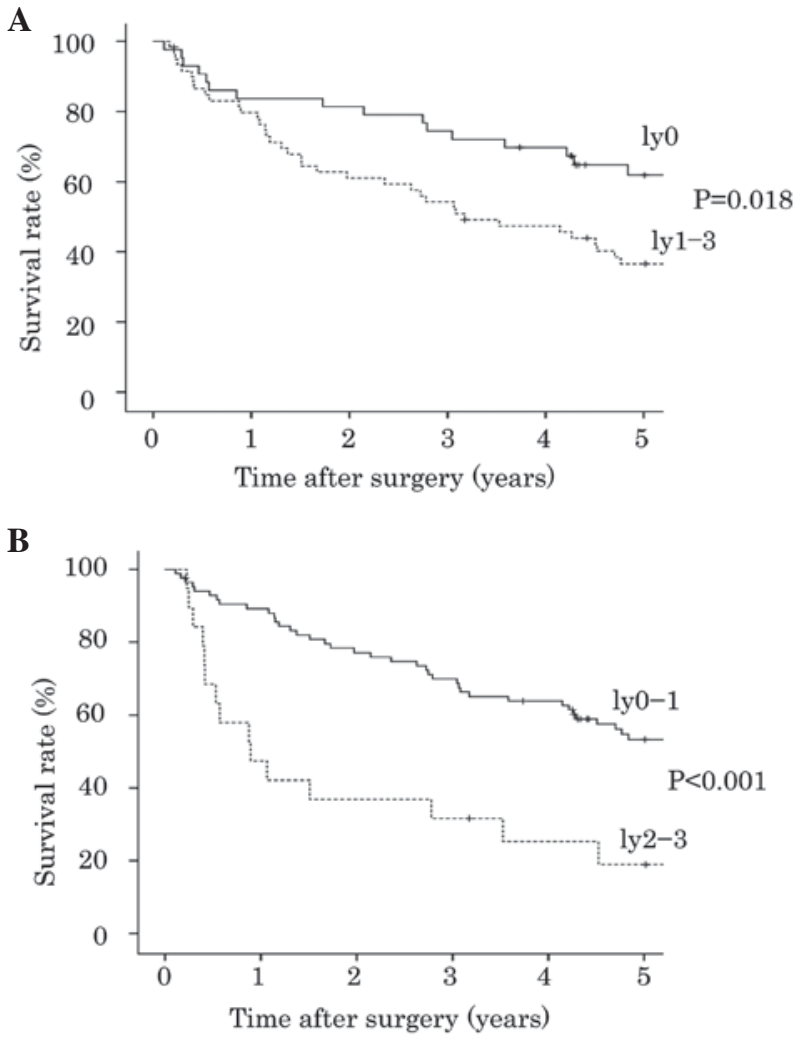

Figure 3. Degree of lymphatic invasion and cumulative survival of patients with lung squamous cell carcinoma. (A) Ly0 vs. 1y1-3; (B) ly0-1 vs. 1y2-3; Kaplan-Meier method and log-rank test.

classification (26). The median postoperative follow-up period was 1,528 days (range, 41-3,837 days). 
Table I. Lymphatic invasion and survival in patients with lung squamous cell carcinoma.

\begin{tabular}{|c|c|c|c|c|}
\hline Variable & $\begin{array}{c}\text { No. of patients } \\
(\%)\end{array}$ & P-value & Hazard ratio & $\begin{array}{c}95 \% \text { Confidence } \\
\text { interval }\end{array}$ \\
\hline Lymphatic invasion & & $<0.001$ & & \\
\hline ly0 & $43(41.7)$ & & 1.854 & $1.390-2.474$ \\
\hline ly1-3 & $60(58.3)$ & & & \\
\hline Lymphatic invasion & & $<0.001$ & & \\
\hline ly0-1 & $84(91.6)$ & & 3.298 & $1.827-5.952$ \\
\hline ly $2-3$ & $19(18.4)$ & & & \\
\hline Lymphatic invasion & & $<0.001$ & & \\
\hline ly0-2 & $96(93.2)$ & & 4.752 & $2.115-10.677$ \\
\hline ly3 & $7(6.8)$ & & & \\
\hline
\end{tabular}

Table II. Lymphatic invasion and clinicopathological features of lung squamous cell carcinoma.

\begin{tabular}{|c|c|c|c|c|}
\hline Variable & $\begin{array}{c}\text { No. of patients } \\
(\%)\end{array}$ & $\begin{array}{l}\text { Ly0-1 } \\
(\%)\end{array}$ & $\begin{array}{l}\text { Ly2-3 } \\
(\%)\end{array}$ & P-value \\
\hline Age at surgery (years) & & & & 0.910 \\
\hline$<68$ & $53(51.5)$ & $43(81.1)$ & $10(18.9)$ & \\
\hline$\geqq 68$ & $50(48.5)$ & $41(82.0)$ & $9(18.0)$ & \\
\hline Gender & & & & 0.230 \\
\hline Male & $97(94.2)$ & $78(80.4)$ & $19(19.6)$ & \\
\hline Female & $6(5.8)$ & $6(100.0)$ & $0(0.0)$ & \\
\hline Tumor size (mm) & & & & 0.028 \\
\hline$\leqq 30$ & 39 (37.9) & $36(92.3)$ & $3(7.7)$ & \\
\hline$>30$ & $64(62.1)$ & $48(75.0)$ & $16(25.0)$ & \\
\hline Lymph node metastasis & & & & $<0.001$ \\
\hline $\mathrm{n}(-)$ & $70(68.0)$ & $66(94.3)$ & $4(5.7)$ & \\
\hline $\mathrm{n}(+)$ & $33(32.0)$ & $18(54.5)$ & $15(45.5)$ & \\
\hline Venous invasion & & & & 0.001 \\
\hline $\mathrm{v}(-)$ & $53(51.5)$ & $50(94.3)$ & $3(5.7)$ & \\
\hline $\mathrm{v}(+)$ & $50(48.5)$ & $34(68.0)$ & $16(32.0)$ & \\
\hline Histological differentiation & & & & 0.047 \\
\hline Well, moderate & $90(87.4)$ & $76(84.4)$ & $14(15.6)$ & \\
\hline Poorly & $13(12.6)$ & $8(61.5)$ & $5(38.5)$ & \\
\hline Stromal type & & & & 0.298 \\
\hline Medullary, intermediate & $70(68.0)$ & $59(84.3)$ & $11(15.7)$ & \\
\hline Scirrhous & $33(32.0)$ & $25(75.8)$ & $8(24.2)$ & \\
\hline Infiltrating pattern & & & & 0.142 \\
\hline INFc(-) & $64(62.1)$ & $55(85.9)$ & $9(14.1)$ & \\
\hline $\operatorname{INFc}(+)$ & $39(37.9)$ & $29(74.4)$ & $10(25.6)$ & \\
\hline
\end{tabular}

$\mathrm{n}(-) / \mathrm{n}(+)$, lymph node metastasis negative/positive; $\mathrm{v}(-) / \mathrm{v}(+)$, venous invasion negative/positive; INFc(-)/INFc(+), infiltrating component negative/positive.

Histological examination. The lung tissue specimens were fixed with $10 \%$ buffered formalin for 24-48 h, embedded in paraffin according to routine techniques, and $4-\mu \mathrm{m}$ sections were sliced at 5-10 mm intervals. Sections were examined using an optical microscope. INF pattern and lymphatic invasion were examined on sections, which were stained with hematoxylin and eosin. Vascular and pleural invasion were examined using Verhoeff-van Gieson staining as follows: Incubation with Verhoeff solution [5\% alcohol hematoxylin, 10\% ferric chloride and Weigert iodine solution (Muto Pure Chemicals 
Table III. Clinicopathological features and survival in patients with lung squamous cell carcinoma.

\begin{tabular}{|c|c|c|c|c|}
\hline Variable & $\begin{array}{c}\text { No. of patients } \\
(\%)\end{array}$ & P-value & Hazard ratio & $\begin{array}{c}95 \% \text { Confidence } \\
\text { interval }\end{array}$ \\
\hline Age at surgery (years) & & 0.131 & & \\
\hline$<68$ & $53(51.5)$ & & 1.502 & $0.885-2.548$ \\
\hline$\geqq 68$ & $50(48.5)$ & & & \\
\hline Gender & & 0.904 & & \\
\hline Male & $97(94.2)$ & & 0.939 & $0.339-2.602$ \\
\hline Female & $6(5.8)$ & & & \\
\hline Tumor size (mm) & & 0.031 & & \\
\hline$\leqq 30$ & $39(37.9)$ & & 1.897 & $1.059-3.396$ \\
\hline$>30$ & $64(62.1)$ & & & \\
\hline Lymph node metastasis & & $<0.001$ & & \\
\hline $\mathrm{n}(-)$ & $70(68.0)$ & & 3.028 & $1.785-5.136$ \\
\hline $\mathrm{n}(+)$ & $33(32.0)$ & & & \\
\hline Lymphatic invasion & & $<0.001$ & & \\
\hline ly0 & $43(41.7)$ & & 1.854 & $1.390-2.474$ \\
\hline ly1-3 & $60(58.3)$ & & & \\
\hline Lymphatic invasion & & $<0.001$ & & \\
\hline ly0-1 & 84 (91.6) & & 3.298 & $1.827-5.952$ \\
\hline ly2-3 & $19(18.4)$ & & & \\
\hline Venous invasion & & 0.145 & & \\
\hline $\mathrm{v}(-)$ & $53(51.5)$ & & 1.486 & $0.873-2.530$ \\
\hline $\mathrm{v}(+)$ & $50(48.5)$ & & & \\
\hline Histological differentiation & & 0.036 & & \\
\hline Well, mod & $90(87.4)$ & & 2.092 & $1.050-4.168$ \\
\hline Poorly & 13 (12.6) & & & \\
\hline Stromal type & & 0.465 & & \\
\hline Medullary, intermediate & $70(68.0)$ & & 1.229 & $0.706-2.139$ \\
\hline Scirrhous & $33(32.0)$ & & & \\
\hline Infiltrating pattern & & 0.003 & & \\
\hline INFc(-) & $64(62.1)$ & & 2.209 & $1.301-3.749$ \\
\hline $\operatorname{INFc}(+)$ & $39(37.9)$ & & & \\
\hline
\end{tabular}

$\mathrm{n}(-) / \mathrm{n}(+)$, lymph node metastasis negative/positive; $\mathrm{v}(-) / \mathrm{v}(+)$, venous invasion negative/positive; INFc(-)/INFc(+), infiltrating component negative/positive.

Co., Ltd., Tokyo, Japan)] for $60 \mathrm{~min}$ at room temperature; and then van Gieson solution [1\% aqueous acid fuchsin: (Muto Pure Chemicals Co., Ltd.)] for $10 \mathrm{~min}$ at room temperature. The degree of lymphatic invasion was classified as follows: Ly0, no lymphatic invasion; ly1, mild lymphatic invasion; ly2, moderate lymphatic invasion; or ly3, severe lymphatic invasion (Fig. 1). The degree of venous invasion was classified as follows: V0, no venous invasion; v1, minimal venous invasion (1 or 2 foci of venous invasion per histological section); v2, moderate venous invasion (3 or 4 foci); or v3, severe venous invasion ( $\geq 5$ foci).

The INF pattern was described as previously reported in gastric cancer studies (15-17): INFa, cancer nests exhibited expanding growth and a distinct border with the surrounding tissues; INFb, characteristics between those of INFa and INFc; and INFc, cancer nests exhibited infiltrative growth and an indistinct border with the surrounding tissues. Since some specimens included two INF patterns, the patients were divided into seven INF categories: INFa, INFa $>$ b, INFa $<$ b, $\mathrm{INFb}, \mathrm{INFb}>\mathrm{c}, \mathrm{INFb}<\mathrm{c}$, and INFc. These seven categories were divided into an INFc(-) group, which consisted of INFa, INFa $>$ b, INFa $<$ b and INFb; and an INFc(+) group, which consisted of INFb $>c$, INFb $<$ c and INFc $(4,6)$.

The degree of lymph node metastasis was classified according to the TNM system as follows: N0, no lymph node metastasis; N1, ipsilateral peribronchial and/or hilar lymph node metastasis; or N2, ipsilateral mediastinal and/or subcarinal lymph node metastasis (26). The stromal type (i.e., the cancer-stroma relationship pattern) was classified as follows: Medullary, with scanty stroma; intermediate, with a quantity of stroma intermediate between the scirrhous and medullary types; and scirrhous, with abundant stroma (15). 
Table IV. Multivariate analysis of clinicopathological features and survival in patients with lung squamous cell carcinoma.

\begin{tabular}{|c|c|c|c|c|}
\hline Variable & $\begin{array}{c}\text { No. of patients } \\
(\%)\end{array}$ & P-value & Hazard ratio & $\begin{array}{c}95 \% \text { Confidence } \\
\text { interval }\end{array}$ \\
\hline Age at surgery (years) & & 0.179 & & \\
\hline$<68$ & $53(51.5)$ & & 1.461 & $0.840-2.540$ \\
\hline$\geqq 68$ & $50(48.5)$ & & & \\
\hline Gender & & 0.784 & & \\
\hline Male & $97(94.2)$ & & 1.157 & $0.408-3.281$ \\
\hline Female & $6(5.8)$ & & & \\
\hline Tumor size (mm) & & 0.083 & & \\
\hline$\leqq 30$ & $39(37.9)$ & & 1.700 & 0.933-3.098 \\
\hline$>30$ & $64(62.1)$ & & & \\
\hline Infiltrating pattern & & 0.058 & & \\
\hline INFc(-) & $64(62.1)$ & & 1.723 & $0.981-3.027$ \\
\hline $\operatorname{INFc}(+)$ & 39 (37.9) & & & \\
\hline Lymphatic invasion & & 0.003 & & \\
\hline ly0-1 & $84(81.6)$ & & 2.580 & $1.376-4.839$ \\
\hline ly2-3 & $19(18.4)$ & & & \\
\hline
\end{tabular}

$\operatorname{INFc(-)/INFc(+),~infiltrating~component~negative/positive.~}$

Statistical analysis. Univariate analyses were performed to identify significant differences between the groups $\left(\chi^{2}\right.$ test, $\mathrm{P}<0.05)$. Cox univariate and multivariate proportional hazard regression analyses were performed to determine the independent effects of individual factors while controlling for the effects of the other factors. Univariate and multivariate analyses were also performed to investigate the association between the degree of lymphatic invasion and patient prognosis. Multivariate analysis was performed for all factors; five representative factors are presented in the present study. Hazard ratios (HRs) with $95 \%$ confidence intervals (CIs) were calculated to assess the impact of individual factors on prognosis. $\mathrm{P}<0.05$ was considered to indicate a statistically significant difference.

Patient survival was measured from the date of surgery until mortality from any cause. Survival curves were constructed using the Kaplan-Meier method and were compared using the log-rank test. All analyses were performed using the SPSS II statistical software package (version 19.0; IBM SPSS, Tokyo, Japan).

\section{Results}

Association between lymphatic invasion and patient survival. The degree of lymphatic invasion was classified into four groups: Ly0 in 43 cases $(41.7 \%)$, ly1 in 41 cases $(39.8 \%)$, ly2 in 12 cases $(11.7 \%)$ and ly 3 in 7 cases $(6.8 \%)$. The association between degree of lymphatic invasion and patient survival is presented in Table I. Analysis using the Kaplan-Meier method and the log-rank test indicated that patients with ly2 exhibited poorer survival compared with patients with ly1 $(\mathrm{P}=0.048$; Fig. 2). However, overall survival was not significantly different between patients with ly0 and ly1 $(\mathrm{P}=0.237)$, or between patients with ly 2 and ly $3(\mathrm{P}=0.138)$. A more statistically significant difference was detected between patients with ly0-1 and 1y2-3 $(\mathrm{P}<0.001)$, compared with between patients with ly0 and ly1-3 ( $\mathrm{P}=0.018$, Fig. 3).

Association between lymphatic invasion and clinicopathological features. The stromal type of SqCC was medullary in 39 cases $(37.9 \%)$, intermediate in 31 cases $(30.1 \%)$, and scirrhous in 33 cases $(32.0 \%)$. The INF patterns were classified as follows: INFa in 11 patients $(10.7 \%)$, INFa $>b$ in 10 patients $(9.7 \%)$, INFb in 43 patients $(41.7 \%)$, INFb $>c$ in 31 patients $(30.1 \%), \mathrm{INFb}<\mathrm{c}$ in 4 patients $(3.9 \%)$, and INFc in 4 patients $(3.9 \%)$; therefore, 64 patients $(62.1 \%)$ were classified as INFc(+) and 39 patients $(37.9 \%)$ were classified as INFc(-). The associations between degree of lymphatic invasion and clinicopathological features are presented in Table II. Ly2-3 was significantly associated with larger tumor size $(\mathrm{P}=0.028)$, lymph node metastasis $(\mathrm{P}<0.001)$, venous invasion $(\mathrm{P}=0.001)$ and poor differentiation $(\mathrm{P}=0.047)$, as compared with ly0-1. Univariate analyses identified five factors that were significantly associated with increased mortality (Table III): Increased tumor size (HR, 1.897; 95\% CI, 1.059-3.396); lymph node metastasis (HR, 3.028; 95\% CI, 1.785-5.136); lymphatic invasion (HR, 3.298; 95\% CI, 1.827-5.952); poor differentiation (HR, 2.092; 95\% CI, 1.050-4.168) and INFc(-) (HR, 2.209; 95\% CI, 1.301-3.749). Scirrhous stromal type was not significantly associated with survival (HR, 1.229; 95\% CI, 0.706-2.139). In addition, multivariate analysis identified ly2-3 as an independent predictor of mortality (HR, 2.580; 95\% CI, 1.376-4.839; Table IV).

\section{Discussion}

The present study investigated the degree of lymphatic invasion and other clinicopathological features of lung SqCC, and 
demonstrated that ly2-3 was associated with higher malignant potential compared with ly0-1. A total of $18 \%$ of patients with lung SqCC had ly2-3, and exhibited higher rates of lymph node metastasis and poorer overall survival compared with those with ly0-1. A previous study reported that vessel invasion was a predictor of poor prognosis in patients with non-small cell lung cancer (8-10). However, the majority of patients in that previous study had adenocarcinoma, and lymphatic invasion has not previously been reported as a potential prognostic factor in patients with non-small cell lung cancer. To the best of our knowledge, this is the first study to report an association between the degree of lymphatic invasion and prognosis in patients with lung SqCC.

Several patients with lung SqCC have undergone surgical resection due to advances in imaging, other diagnostic techniques, and operative procedures $(27,28)$. In these patients, the most important prognostic factor is thought to be pathological stage according to the TNM classification system. Although lobectomy and lymph node dissection are standard surgical procedures, some patients with poor pulmonary function only undergo limited resection without lymph node dissection. In these patients, lymph node metastasis ( $\mathrm{N}$ factor) is histologically unclear, and the pathological stage cannot be determined. The main histological information is obtained from the primary tumor ( $\mathrm{T}$ factor, which predominantly accounts for tumor size), which is insufficient to determine prognosis. Lung cancer is evaluated according to morphological features, including histological type, histological differentiation, pleural invasion, blood vessel invasion and lymphatic invasion (8-10). Evaluations of cancer in other organs include histological factors, such as the INF pattern and stromal type (4-7,29,30). Therefore, the present study considered it important to evaluate these factors in lung cancer, in combination with the conventional factors. Various treatments are currently available for patients who develop postoperative recurrence of lung adenocarcinoma; however, there are not any effective treatments available for patients who develop postoperative recurrence of lung SqCC (20-24). Therefore, the identification of factors that predict patient prognosis is important for $\mathrm{SqCC}$, in order to enable early detection and treatment of recurrence, and to determine the need for postoperative adjuvant therapy. In addition, adenocarcinoma, SqCC and large cell carcinoma are all categorized as non-small cell carcinoma. However, $35 \%$ of non-small cell carcinoma cases are $\mathrm{SqCC}$, and $\mathrm{SqCC}$ must be studied separately from adenocarcinoma.

Our previous study reported an association between INF pattern and survival in patients undergoing treatment for SqCC of the lung (6). The present study evaluated the local aggressiveness of SqCC by the degree of lymphatic invasion. When patients were classified into two groups, namely, those with positive (ly1-3) or negative (ly0) lymphatic invasion, a significant difference in survival was observed between them. However, there was a more statistically significant difference in survival between patients with ly0-1 and ly2-3. Univariate analysis indicated a significant difference in survival between patients with ly1-3 and ly0; however, the HR was 1.854, which was lower than the HR of 3.298 for the comparison of survival between patients with ly0-1 and ly2-3. Lymph node metastasis was excluded from the multivariate analysis since there was a moderate linear relationship between lymphatic invasion and lymph node metastasis. This finding may help to predict the prognosis in patients undergoing limited resection. In the present study, patients with ly2-3 exhibited a significantly higher rate of lymph node metastasis compared with those with ly0-1 $(\mathrm{P}<0.001)$. Since the prediction of lymph node metastasis is important in patients with lung cancer who may undergo limited resection, the authors of the present study aim to conduct further studies to clarify the relationship between lymph node metastasis and the morphological features of SqCC using immunohistochemical/molecular analyses. The present study also analyzed the relationship between venous invasion and prognosis, but found no significant differences in prognosis among the categories of blood vessel invasion (data not shown).

In conclusion, the degree of lymphatic invasion in lung $\mathrm{SqCC}$ is associated with local tumor aggressiveness, and may be a useful indicator of prognosis.

\section{References}

1. Goldstraw P, Crowley J, Chansky K, Giroux DJ, Groome PA, Rami-Porta R, Postmus PE, Rusch V and Sobin L; International Association for the Study of Lung Cancer International Staging Committee; Participating Institutions: The IASLC Lung Cancer Staging Project: Proposals for the revision of the TNM stage groupings in the forthcoming (seventh) edition of the TNM classification of malignant tumours. J Thorac Oncol 2: 706-714, 2007.

2. Chung CK, Zaino R, Stryker JA, O'Neill M Jr and DeMuth WE Jr: Carcinoma of the lung: Evaluation of histological grade and factors influencing prognosis. Ann Thorac Surg 33: 599-604, 1982.

3. Gajra A, Newman N, Gamble GP, Abraham NZ, Kohman LJ and Graziano SL: Impact of tumor size on survival in stage IA non-small cell lung cancer: A case for subdividing stage IA disease. Lung Cancer 42: 51-57, 2003.

4. Ito E, Ozawa S, Kijima H, Kazuno A, Nishi T, Chino O, Shimada H, Tanaka M, Inoue S, Inokuchi $\mathrm{S}$ and Makuuchi H: New invasive patterns as a prognostic factor for superficial esophageal cancer. J Gastroenterol 47: 1279-1289, 2012.

5. Okada K, Kijima H, Imaizumi T, Hirabayashi K, Matsuyama M, Yazawa N, Dowaki S, Tobita K, Ohtani Y,Tanaka M, et al: Clinical significance of wall invasion pattern of subserosa-invasive gallbladder carcinoma. Oncol Rep 28: 1531-1536, 2012.

6. Masuda R, Kijima H, Imamura N, Aruga N, Nakamura Y, Masuda D, Takeichi H, Kato N, Nakagawa T, Tanaka M, et al: Tumor budding is a significant indicator of a poor prognosis in lung squamous cell carcinoma patients. Mol Med Rep 6: 937-943, 2012.

7. Yokota T, Kunii Y, Teshima S, Yamada Y, Saito T, Takahashi M, Kikuchi S and Yamauchi H: Significant prognostic factors in patients with early gastric cancer. Int Surg 85: 286-290, 2000.

8. Harpole DH Jr, Herndon JE II, Young WG Jr, Wolfe WG and Sabiston DC Jr: Stage I nonsmall cell lung cancer. A multivariate analysis of treatment methods and patterns of recurrence. Cancer 76: 787-796, 1995.

9. Ichinose Y, Yano T, Asoh H, Yokoyama H, Yoshino I and Katsuda Y: Prognostic factors obtained by a pathologic examination in completely resected non-small-cell lung cancer. An analysis in each pathologic stage. J Thorac Cardiovasc Surg 110: 601-605, 1995.

10. Duarte IG, Bufkin BL, Pennington MF, Gal AA, Cohen C, Kosinski AS, Mansour KA and Miller JI: Angiogenesis as a predictor of survival after surgical resection for stage I non-small-cell lung cancer. J Thorac Cardiovasc Surg 115: 652-659, 1998.

11. Crabbe MM, Patrissi GA and Fontenelle LJ: Minimal resection for bronchogenic carcinoma. An update. Chest 99: 1421-1424, 1991.

12. Martini N, Rusch VW, Bains MS, Kris MG, Downey RJ, Flehinger BJ and Ginsberg RJ: Factors influencing ten-year survival in resected stages I to IIIa non-small cell lung cancer. J Thorac Cardiovasc Surg 117: 32-38, 1999.

13. Hylkema MN, Sterk PJ, de Boer WI and Postma DS: Tobacco use in relation to COPD and asthma. Eur Respir J 29: 438-445, 2007. 
14. Gratziou Ch, Florou A, Ischaki E, Eleftheriou K, Sachlas A, Bersimis $\mathrm{S}$ and Zakynthinos S: Smoking cessation effectiveness in smokers with COPD and asthma under real life conditions. Respir Med 108: 577-583, 2014.

15. Japanese Gastric Cancer Association: Japanese classification of gastric carcinoma: 3rd English edition. Gastric Cancer 14: 101-112, 2011.

16. Maehara Y, Oshiro T, Adachi Y, Ohno S, Akazawa K and Sugimachi K: Growth pattern and prognosis of gastric cancer invading the subserosa. J Surg Oncol 55: 203-208, 1994.

17. Haraguchi M, Yamamoto M, Saito A, Kakeji Y, Orita H Korenaga D and Sugimachi K: Prognostic value of depth and pattern of stomach wall invasion in patients with an advanced gastric carcinoma. Semin Surg Oncol 10: 125-129, 1994.

18. Dembitzer FR, Flores RM, Parides MK and Beasley MB Impact of histological subtyping on outcome in lobar vs sublobar resections for lung cancer: A pilot study. Chest 146: 175-181, 2014

19. Koike T, Koike T, Yoshiya K, Tsuchida M and Toyabe S: Risk factor analysis of locoregional recurrence after sublobar resection in patients with clinical stage IA non-small cell lung cancer. J Thorac Cardiovasc Surg 146: 372-378, 2013.

20. Rossi A, Ricciardi S, Maione P, de Marinis F and Gridelli C: Pemetrexed in the treatment of advanced non-squamous lung cancer. Lung Cancer 66: 141-149, 2009.

21. Sandler A, Gray R, Perry MC, Brahmer J, Schiller JH, Dowlati A, Lilenbaum R and Johnson DH: Paclitaxel-carboplatin alone or with bevacizumab for non-small-cell lung cancer. N Engl J Med 355: 2542-2550, 2006.

22. Reck M, von Pawel J, Zatloukal P, Ramlau R, Gorbounova V, Hirsh V, Leighl N, Mezger J, Archer V, Moore N and Manegold C: Phase III trial of cisplatin plus gemcitabine with either placebo or bevacizumab as first-line therapy for nonsquamous non-small-cell lung cancer: AVAil. J Clin Oncol 27: 1227-1234, 2009.
23. Rosell R, Perez-Roca L, Sanchez JJ, Cobo M, Moran T, Chaib I, Provencio M, Domine M, Sala MA, Jimenez U, et al: Customized treatment in non-small-cell lung cancer based on EGFR mutations and BRCA1 mRNA expression. PLoS One 4: e5133, 2009.

24. Hong J, Kyung SY, Lee SP, Park JW, Jung SH, Lee JI, Park SH, Sym SJ, Park J, Cho EK, et al: Pemetrexed versus gefitinib versus erlotinib in previously treated patients with non-small cell lung cancer. Korean J Intern Med 25: 294-300, 2010.

25. Brierley JD, Gospodarowicz MK and Wittekind C (eds): TNM Classification of Malignant Tumors, 7th edition. Wiley, Oxford, 2009.

26. Travis WD, Brambilla E, Müller-Hermelin HK and Harris CC (eds): World Health Organization Classification of Tumors Pathology and Genetics of Tumours of the Lung, Pleura, Thymus and Heart. IARC Press, Lyon, 2004.

27. Beattie G, Bannon F and McGuigan J: Lung cancer resection rates have increased significantly in females during a 15 -year period. Eur J Cardiothorac Surg 38: 484-490, 2010.

28. Martin-Ucar AE, Waller DA, Atkins JL, Swinson D, O'Byrne KJ and Peake MD: The beneficial effects of specialist thoracic surgery on the resection rate for non-small-cell lung cancer. Lung Cancer 46: 227-232, 2004.

29. Masuda R, Kijima H, Imamura N, Aruga N, Nakazato K, Oiwa K, Nakano T, Watanabe H, Ikoma Y, Tanaka M, et al: Laminin-5 2 chain expression is associated with tumor cell invasiveness and prognosis of lung squamous cell carcinoma. Biomed Res 33: 309-317, 2012.

30. Okada K, Kijima H, Imaizumi T, Hirabayashi K, Matsuyama M, Yazawa N, Oida Y, Dowaki S, Tobita K, Ohtani Y, et al: Stromal laminin-5gamma2 chain expression is associated with the wall-invasion pattern of gallbladder adenocarcinoma. Biomed Res 30: 53-62, 2009. 